Journal of Al Azhar University Engineering Sector

Vol. 14, No. 52, July 2019, 1113-1122

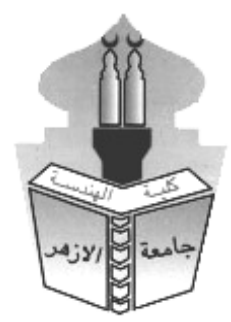

\title{
ON-GRID PHOTOVOLTAIC SYSTEM MAXIMUM POWER POINT TRACKING USING PERTURB AND OBSERVE ALGORITHM
}

\author{
Mohammed Kamal Ahmed \\ Electrical Power and Machines Department, Faculty of Engineering, Al-Azhar \\ University, Cairo, Egypt. \\ mkalshaear@yahoo.com
}

\begin{abstract}
The energy generated from Photovoltaic (PV) arrays is mainly take full benefit with a maximum power point tracking (MPPT) systems. The perturb \& observe algorithm technique is used, in which periodically perturbs the operational point of PV array, and compare the PV power before and after the perturbation. In this paper, the recital of a three-phase grid connected system is considered. The system includes two (100-kw PV modules), DC/DC converter and DC/AC inverter. The control system composed of two control instruments in the planned PV system where the first is for (MPPT) of the PV module and other is for infusing the ideal measure of capacity to Grid. The whole system is designed and simulated by MATLAB (Simulink). By the simulation consequence can expect the real MPPT photovoltaic system performance.
\end{abstract}

Key words: PV arrays, On-grid system, Maximum power point tracking MPPT, Perturb \& observe algorithm,

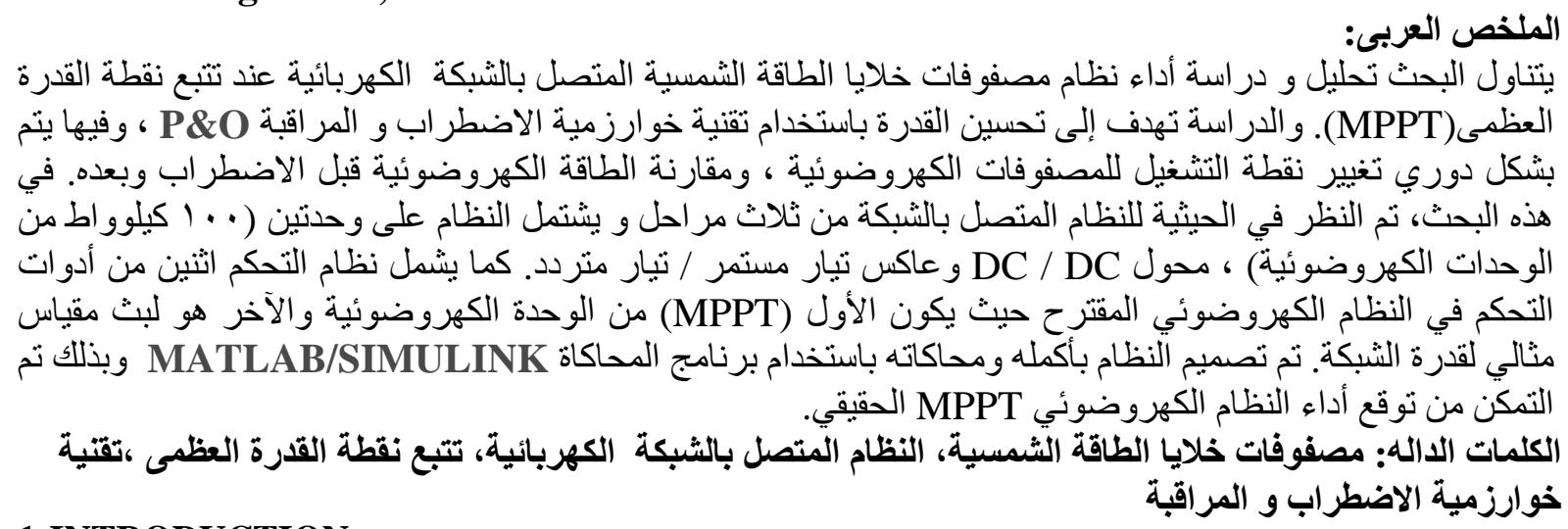

\section{1-INTRODUCTION}

Photovoltaic (PV) power generation regimes have received important consideration from investigators in the course of most recent couple of years to diminish the ecological pollution associated with traditional electric power generation. The financial expediency of PV energy generation regimes is associated to the price of the cells and the total of energy that the arrays can deliver over their lifetime [1]-[2]. Currently, the control calculations utilized for the boost power created from PV exhibits are generally identified as maximum power point tracking (MPPT) calculations. These power conditioners ensure that PV exhibits work near their purpose of most extreme effectiveness under any atmosphere conditions. This is chiefly vital for variable illumination levels, because the productivity of PV-modules is low when the working point is far from MPPT [3]. The MPPT strategies proposed in some specialized writing can be arranged essentially as Perturb and Observe (P\&O), Incremental Conductance (IC), and Temperature Gradient (TG) systems [1]. The P\&O calculation is normal as a result of its simple execution [25]. The Perturb - and- observe strategy, is known as the interruption technique, it is basically a test and mistake strategy. The PV controller expands the direction reference signal for the inverter output control by a PV, and after that distinguishes the real power output. Effectiveness is for sure expanded, it will increment again until the output control starts to diminish, at which the 
controller diminishes the reference to stay far from the breakdown of the due PV delivered by strongly nonlinear characteristic of PV.

The converter operating voltage is changed marginally at each control step and the subsequent variety of power output is estimated. In the event that $\mathrm{P} \& \mathrm{O}$ has caused a power increment, the voltage is additionally altered in a similar course; if not, a backwards perturbation is applied. Regardless of its cost-adequacy and fast preparing, the system execution has been

exceptional. In the MPPT P\&O controller, the alteration of the working point is accomplished by changed reference voltage of controller.

\section{2-MODELING OF SOLAR PV-ARRAY}

The main benefit of the modular PV systems is that may be simply implemented in existing buildings and can installed anywhere. There are certain various models, which can fit on a different type of houses or buildings to realize a better performance. However, behavior analysis of this system in real conditions is generally a difficult mission because several issues should consider for example the partial shading.

The functioning of PV systems is negatively affected if all its modules are inhomogeneous irradiated. The modules in a series connected array are enforced to carry the same current even though a few modules under shade produce less photocurrent [6]. The shaded PVmodules may become reverse-biased and acts as loads and dissipates power from fully irradiated modules in the form of temperature rise. In the event that the system isn't properly secured, problem area issue [2] can emerge and in a few cases, the system can be irreversibly harmed.

The PV-cell is a simple photo diode consisting of n-type and p-type semiconductor material that produces power, when subjected to solar irradiation.

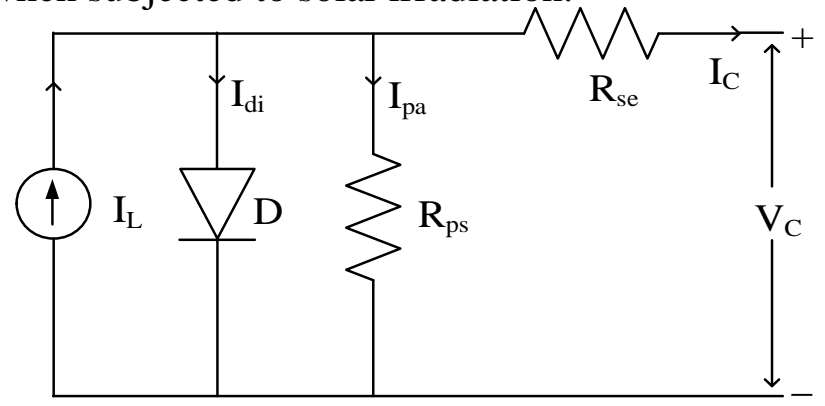

Fig. 1 PV cell model with single shunt diode equivalent circuit.

To explain the electrical performance of PV-cell, the circuit model with single shunt diode or two shunt diodes may be used. In this work the single shunt diode equivalent model as exposed

Fig. 1 has been used, because of ease in simulation and less complexity.

The precise model of PV cell can be carried out by using the equations provided in [7]. At the output, the current obtained due to illumination of solar irradiation is given by:

$I_{C}=I_{L}-\left(I_{p a}+I_{d i}\right)$

(1)

Where, $\mathbf{I}_{\mathbf{L}}$ is the current establish from PV-cells due to solar irradiation, $\mathbf{I}_{\mathbf{p a}}$ is current flowing in shunt resistance and $\mathbf{I}_{\mathbf{d i}}$ is the current flowing in diode.

$$
\begin{aligned}
& I_{d i}=I_{0 d}\left[\exp \left(\frac{V_{C}+I_{C} R_{s e}}{V_{t} a}\right)-\mathbf{1}\right] \\
& I_{p a}=\frac{V_{C}+I_{C} R_{S e}}{R_{p s}}
\end{aligned}
$$


$I_{C}=I_{L}-I_{0 d}\left[\exp \left(\frac{V_{C}+I_{C} R_{S e}}{V_{t} a}\right)-1\right]-\frac{V_{C}+I_{C} R_{S e}}{R_{p s}}$

Where, $I_{0 \mathrm{~d}}$ is the leakage current, $\mathrm{V}_{\mathrm{C}}$ is generated voltage from PV-module, $\mathrm{R}_{\mathrm{se}}$ and $\mathrm{R}_{\mathrm{ps}}$ are the equivalent resistance of PV module are connected in series and shunt respectively. The equivalent thermal voltage of $\mathrm{PV}$ cell is characterized by $\mathrm{V}_{\mathrm{t}}$ and is given by [8]:

$\mathrm{V}_{\mathrm{t}}=\mathrm{N}_{\mathrm{S}} \mathrm{kT}_{0} / \mathrm{q}_{\mathrm{e}}$

Where, $\mathrm{N}_{\mathrm{S}}$ is number of cells which they are in series connection in a string of PV module, $\mathbf{k}$ is the "Boltzmann-constant $\left(1.3806503 \times 10^{-23} \mathrm{~J} / \mathrm{K}\right)$ ", $T_{0}$ is the temperature at $\mathrm{p}$-n junction, $\mathrm{q}_{\mathrm{e}}$ is "electron charge and its value is $1.60217646 \times 10^{-19} \mathrm{C}^{\prime}$. Due to $\mathrm{PV}$-cell exposed to solar irradiation, the load current by:

$I_{L}=\frac{G}{G_{n}}\left(I_{p s c}+K_{I} \Delta_{T}\right)$

Whereas $\mathrm{G}$ in (W/Sq.m) is the solar-irradiation at normal operating conditions, $\mathrm{G}_{\mathrm{n}}$ in (W/Sq.m) is sun-irradiation at normal temperature, $\mathrm{I}_{\mathrm{psc}}$ is short-circuit current generated by PV-module at normal temperature of $25^{\circ} \mathrm{C}$ and standard solar irradiation of $(1000$ W/Sq.m $), \mathrm{K}_{\mathrm{I}}$ is temperature coefficient under short circuit conditions of PV-module and $\Delta_{\mathrm{T}}$ is the difference between operating temperature $T_{0}$ and normal temperature $T_{n}$ (in kelvin).

The saturated current at minimal temperature and specified by:

$I_{n 0}=\frac{I_{p s c}}{\exp \left(V_{p o c} / a V_{n t}\right)-1}$

$V_{\text {poc }}$ is the open-circuit voltage at normal temperature and $V_{n t}$ is the thermal voltage produced by $\mathrm{N}_{\mathrm{s}}$ cells connected in series in one string of module at rated temperature.

where the reverse saturated diode current is dependent on temperature and is given as:

$I_{0}=\exp \left[\frac{q E_{g}}{a k}\left(\frac{1}{T_{n}}-\frac{1}{T_{0}}\right)\right] I_{n 0}\left(\frac{T_{n}}{T_{0}}\right)^{3}$

The energy of semiconductor materials is represented by $\mathrm{E}_{\mathrm{g}}$ and its value is "(1.12-eV) for polycrystalline silicon at $25^{\circ} \mathrm{C} "$.

3-THE MAXIMUM POWER POINT TRACKING PROCEDURE

As the solar radioactivity varies from time to time, the DC converter has an imperative role in driving the MPPT system. As expressed in maximum power exchange theory, the load will get its pinnacle control, if the estimation of load impedance is proportional to complex conjugate of interior impedance of supply system. Along these lines, to drive the PV arrays at MPP, the load impedance and interior impedance must to be matched.

The interior resistance of PV-module would be varied by varying insolation. The load resistance will be matched with interior resistance of PV-module by using DC/DC converter connected to MPPT controller. The MPPT regulator drive appropriate value of duty cycle that will be fed to (PWM) generator, which produces essential triggering signal for the switch existing in DC/DC converter.

The aim of DC/DC converters is to raise or to reduce PV voltage to a suitable value, so that the PV-system may be interfaced to grid or load. The DC/DC converters like buck, boost, buck-boost are a suitable converter can be selected depending on application. For high voltage applications, boost converter is best one, it was simulated for increasing the PV voltage. The output voltage $V_{o d}$, input voltage $V_{i d}$ and duty-cycle $d$ are related by using equation [10]. 


$$
V_{a d}=\frac{V_{i d}}{(1-d)}
$$

The $\mathrm{P} \& \mathrm{O}$ procedure as mentioned in $[8,9]$ has been implemented. The current $\mathrm{I}_{\mathrm{A}}$ and voltage $\mathrm{V}_{\mathrm{A}}$ of PV arrays at present step $\left(\mathrm{k}^{\mathrm{th}}\right)$ and the previous step $\left((\mathrm{k}-1)^{\mathrm{th}}\right)$ will be measured. Further, the power at present step $\mathrm{P}_{\mathrm{A}}(\mathrm{k})$ and previous step $\mathrm{P}_{\mathrm{A}}(\mathrm{k}-1)$ will be calculated. If power at present step $\mathrm{P}_{\mathrm{A}}(\mathrm{k})$ is greater than that of power at previous step $\mathrm{P}_{\mathrm{A}}(\mathrm{k}-1)$ and if the voltage $\mathrm{V}_{\mathrm{A}}(\mathrm{k})$ is greater than that of $\mathrm{V}_{\mathrm{A}}(\mathrm{k}-1)$, then the tracking will continue on left-side of MPP, by increasing the duty factor with a small value. At the same time, if power $\mathrm{P}_{\mathrm{A}}(\mathrm{k})$ is less than that of $\mathrm{P}_{\mathrm{A}}(\mathrm{k}-1)$ and if the voltage $\mathrm{V}_{\mathrm{A}}(\mathrm{k})$ is greater than that of $\mathrm{V}_{\mathrm{A}}(\mathrm{k}-1)$, then the tracking will continue on the right-side of MPP by decreasing duty cycle with a small value. The flow diagram is observable in Fig. 2.

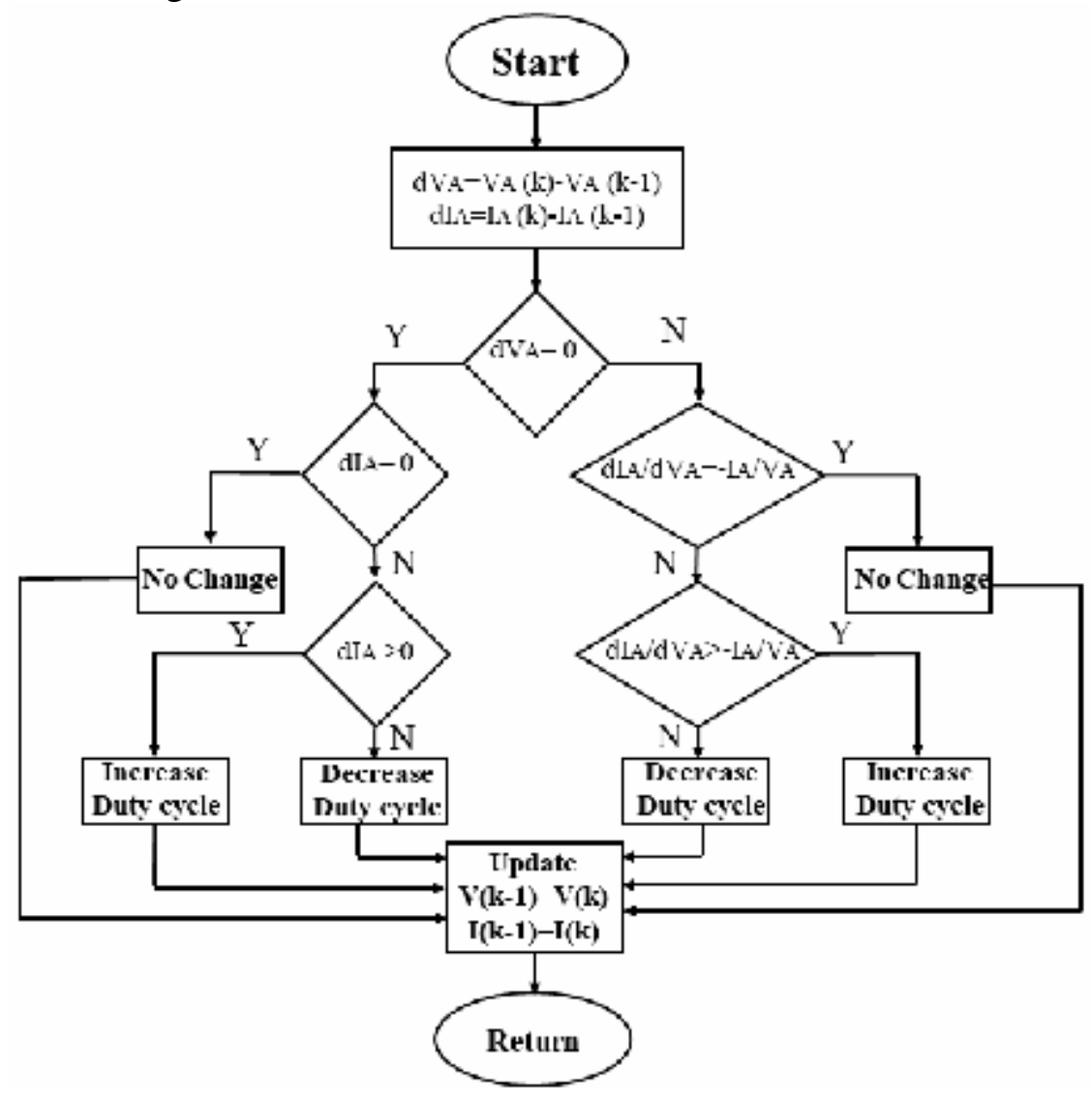

Fig.2 Flow-Chart of Incremental Conductance (INC) Algorithm

The privilege of this algorithm is that it is easier to execute and also the cost is low. The disadvantage related to algorithm is cannot tracks the optimal value and will be continuously having an oscillation near to optimal value of MPP. The improvement in this technique has been suggested in $[10,11]$. The INC algorithm depends upon reality that the differentiation of PV power (at MPP) with respected to voltage equal zero and it also depends upon the slope of $\mathrm{P}-\mathrm{V}$ characteristics. The precise model of (INC) algorithm may be described by equations as in [12].

$\frac{d P_{A}}{d V_{A}}=\frac{d\left(V_{A} I_{A}\right)}{d V_{A}}=I_{A}+V_{A} \frac{d I_{A}}{d V_{A}}=0$

For the condition of MPP the equation (10) may be written as: 
$\frac{d I_{A}}{d V_{A}}=-\frac{I_{A}}{V_{A}}$

The right-hand component in equation (11) indicates the instant conductance of PV array, but in contradictory direction, whereas, the left-hand component indicates the incremental conductance at MPP. The other conditions for tracking MPP on the slope of P-V characteristics are given by:

$\frac{d I_{A}}{d V_{A}}>-\frac{I_{A}}{V_{A}}$

$\frac{d I_{A}}{d V_{A}}<-\frac{I_{A}}{V_{A}}$

Equation (10) represents the condition of $\frac{\mathrm{dP}_{\mathrm{A}}}{\mathrm{dv}_{A}}>0$ and it also indicates that the driving point is lying on the left-side of MPP. Whereas, the eq (10) represents the condition of $\frac{\mathrm{dP}_{A}}{\mathrm{dv}_{A}}<0$ and indicates that the driving point is on right-side of MPP. Based on the above statements, the flow diagram of INC algorithm well be interduces in details in simulation program.

As the algorithm starts, the current value of the voltage \& current will be measured and from the preceding cycle, the previous value of the voltage \& current will be obtained.

Further the values of $\mathrm{dV}_{\mathrm{A}}$ and $\mathrm{dI}_{\mathrm{A}}$ will be calculated. If there is no change in solar irradiation and if the values of $\mathrm{dV}_{\mathrm{A}}$ and $\mathrm{dI}_{\mathrm{A}}$ are equal to zero, then algorithm is tracking MPP. If the value of $\mathrm{dV}_{\mathrm{A}}=0$ and $\mathrm{dI}_{\mathrm{A}}>0$, then it indicates that there is rise in solar irradiation causing the algorithm to increase the value of MPP.

Similarly, if the value of $\mathrm{dV}_{\mathrm{A}}=0$ and $\mathrm{dI}_{\mathrm{A}}<0$, then it indicates that there is decrease in solar irradiation, initiating the algorithm to lower the MPP. In this way, the driving point will be moving on the slope present on either side of MPP, till it reaches the optimum value of MPP. The drawback of this algorithm is that it is may complicated when compared to that of $\mathrm{P} \& \mathrm{O}$ algorithm, but the tracking efficiency is quite good under varying insolation levels. Also, response time for tracking optimum value of MPP depends upon value of fixed-step size used in this algorithm. The improvement in this algorithm is introduction of variable-step size, as proposed in [13].

\section{4- ON-GRID PHOTOVOLTAIC SYSTEM SIMULINK MODEL}

The Simulink model presented in Fig. 3, it is consisting of two PV arrays $100.7 \mathrm{~kW}$ and100.1 $\mathrm{kW}$, and they are transporting a maximum of $(200.8-\mathrm{kW})$ at $\left(1000-\mathrm{W} / \mathrm{m}^{2}\right)$ sun irradiance, two boost-converters with switching frequency $(5-\mathrm{kHz})$ connected in parallel. The boost-converter boosts DC-voltage (PV natural voltage) from (273.5-V) to (500-V).

This converter using a MPPT system which automatically vary the duty cycle to produce the required voltage to derive maximum power.

The switching duty cycle is improved by two MPPT regulator that uses the Incremental Conductance and Integral Controller technique. The 3-phase two-level voltage source converter (VSC) with carrier frequency $1980-\mathrm{Hz}$ that converts the $(500-\mathrm{V})$ DC-bus voltage to 3-phase

(260-V) AC and maintains unity power factor. The VSC control system utilizes two control loops: an external control loop which controls DC-link voltage to (+/- 250-V) and an internal control loop which controls $\mathrm{I}_{\mathrm{R}}$ (active components) and $\mathrm{I}_{\mathrm{Q}}$ (reactive components) grid currents. $I_{R}$ is reference current output from DC-voltage of external controller. $I_{Q}$ is reference current and it is usual zero to keeps unity power factor. $V_{R}$ (active components) and $V_{Q}$ (reactive components) voltage outputs of the current controller are converted to three modulating signals $\mathrm{U}_{\text {ref_abc }}$ used by the PWM three-level pulse generator. 
The control system running by a sample time of $(50-\mu \mathrm{s})$ for voltage and current controllers in addition to the PLL synchronization unit. In the Simulink model, pulse generators of Boost and VSC-converters use a fast sample time of $(1-\mu s)$ in order to have a suitable accuracy of PWM waveforms. The harmonic filter with (20-kvar) capacitor bank filtering harmonics generated by VSC. The system is connected to utility grid model via (200-kVA 260V/25kV) three-phase

two- winding coupling-transformer.

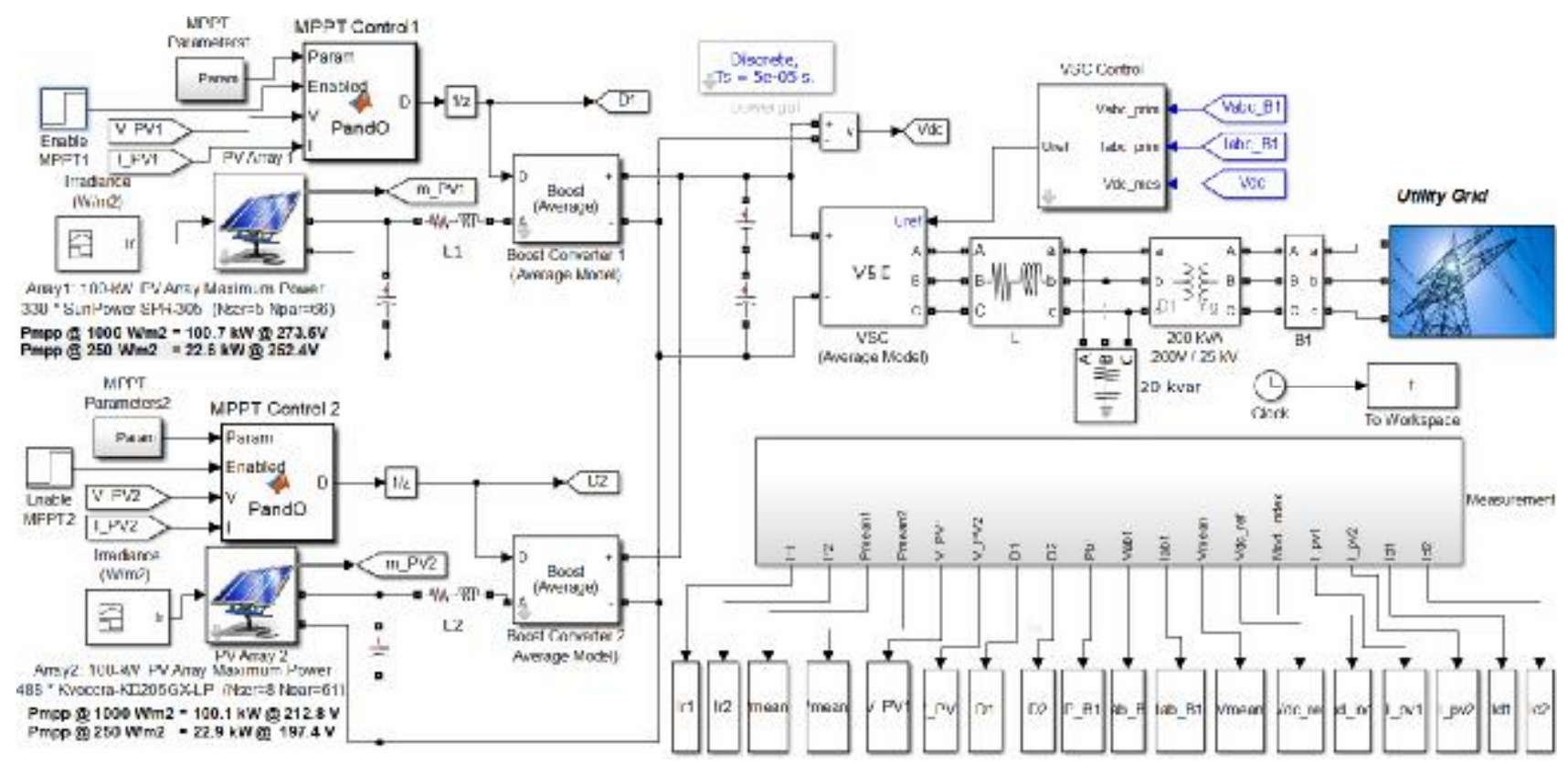

Fig. 3 On-Grid photovoltaic system Simulink model

\section{5- SIMULATION RESULTS:}

To analyze and compare the results obtained from the above mentioned MPPT algorithms in terms of tracking efficiency, a varying irradiation level of solar insolation has been fed to PV array. The two PV arrays simulation results showing that current and output voltage as the output from the PV arrays as seen from Fig. 4 and Fig. 5, also the PV Arrays diode currents waveforms varied with irradiance level as seen from Fig.6. The values of current and voltage are changing with the change in the value of irradiance as displayed the irradiance variation with time in Fig. 7. It's clear from Fig. 10 that the output waveform of simulated output voltage from the Boost-converter always hang near its reference value. The voltage output from boost converter also gets effected due to change in output voltage of PV array and also due to change in duty factor. The variation of duty factor and modulation index as they shown in Fig. 8 and Fig 9 respictivaly.

The action of the modulation index of the DC/DC converter control continues changing with the goal that output voltage can follow the perfect voltage.

The output current of PV array will decrease due to decrease in irradiation causing the power of PV arrayd to decrease as shown in Fig. 11. At first the control is blocked, we can see the impacts of this on waveform, after some time it's blocking is expelled from it and result are apparent.

The output waveform shows us that with such a control loop we get perfectly sinusoidal voltage and current waveforms as shown in Fig. 12 and Fig 13 respictivaly. Correspondingly, with MPPT can enabling after some instance can observed from Fig.14 that, the system power keeps on tracking maximum AC real power delivered to Grid. The input parameters which will control the output power of PV array are solar irradiation and temperature. In the figures below, it may be observed that with the change in irradiation level, the output voltage of PV array decreases with a small value but the output current gets more effected leading to decrease in PV output power. 
ON-GRID PHOTOVOLTAIC SYSTEM MAXIMUM POWER POINT TRACKING USING PERTURB AND OBSERVE ALGORITHM

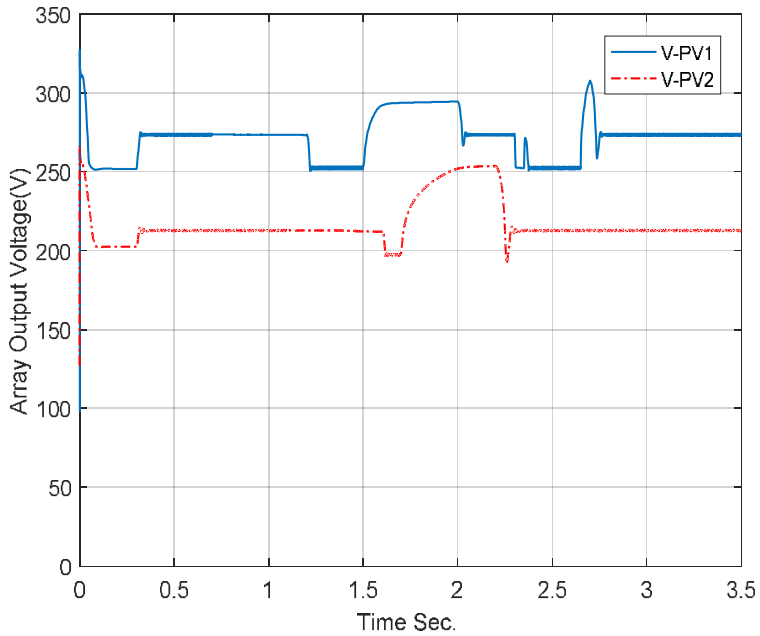

Fig.4. The two PV arrays output voltage

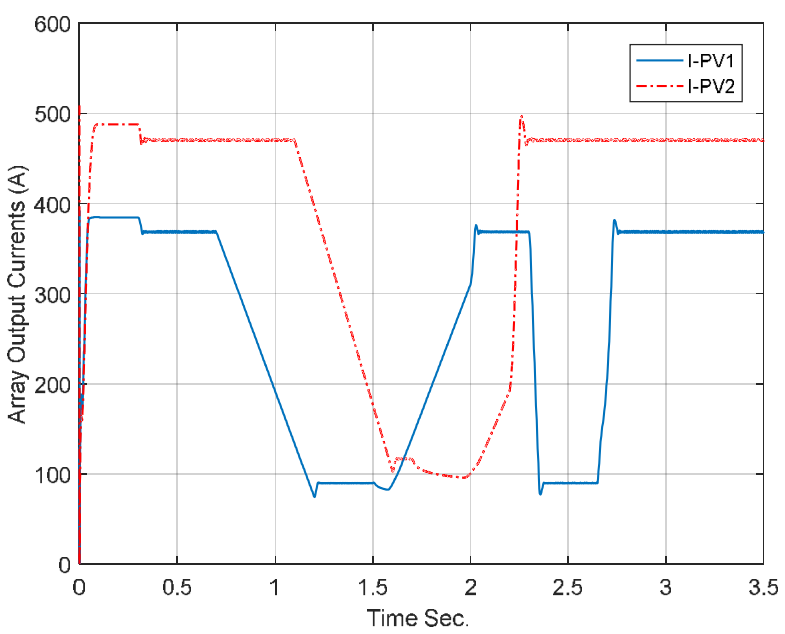

Fig.5. The two PV arrays output current

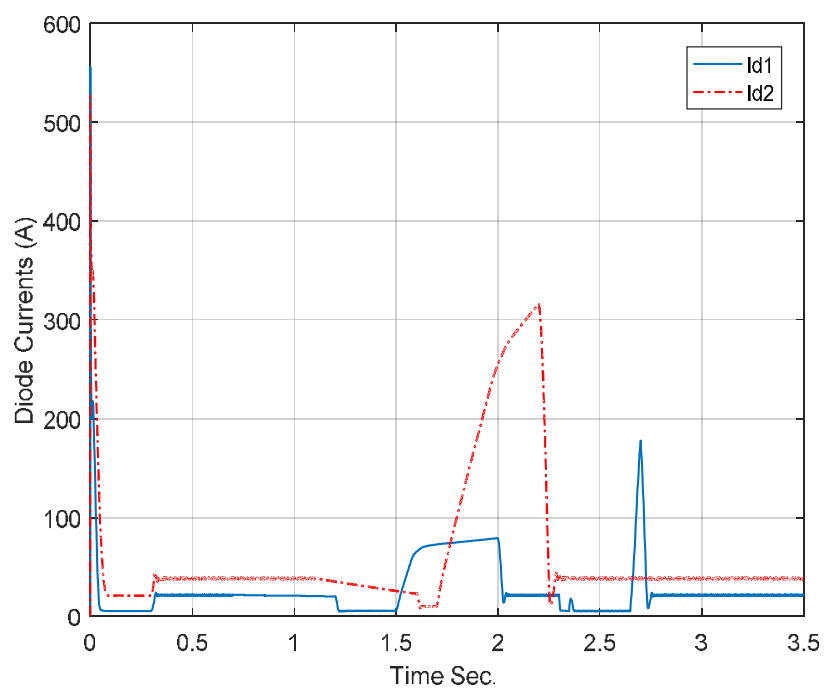

Fig.6. PV arravs diode currents waveform.

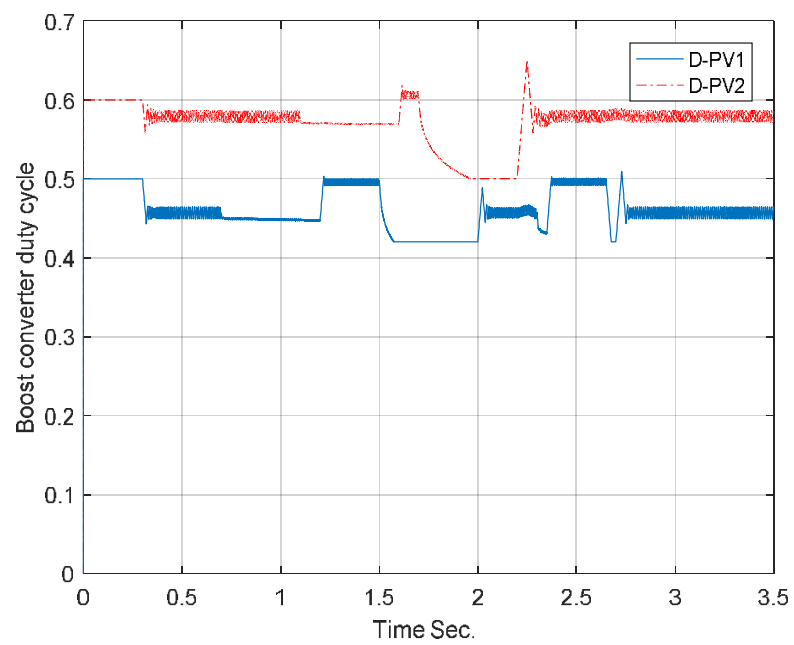

Fig.8. Boost converter duty cycle reference value of two PV arrays

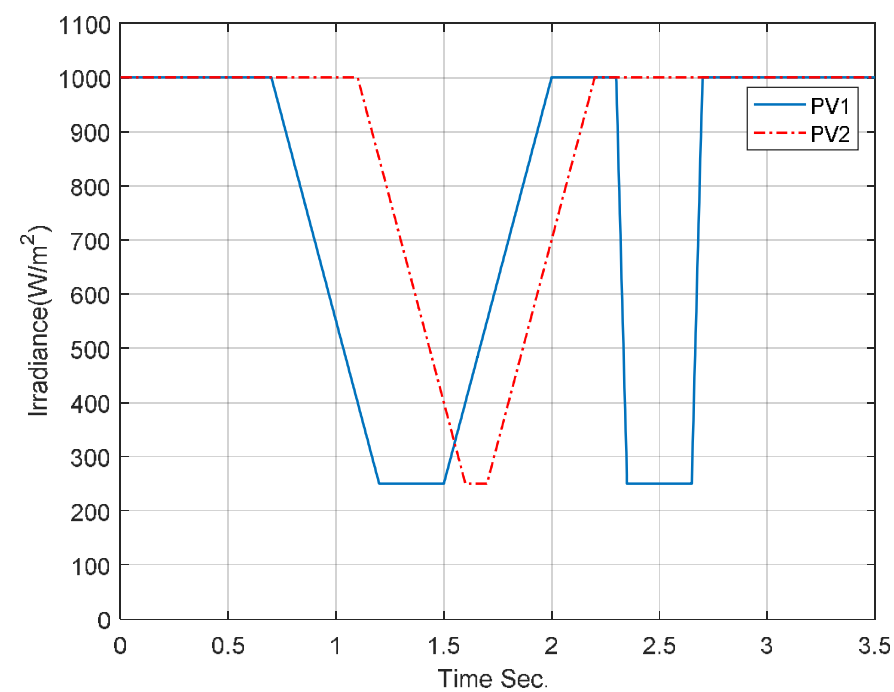

Fig.7. The variation of sun irradiance on two PV arravs

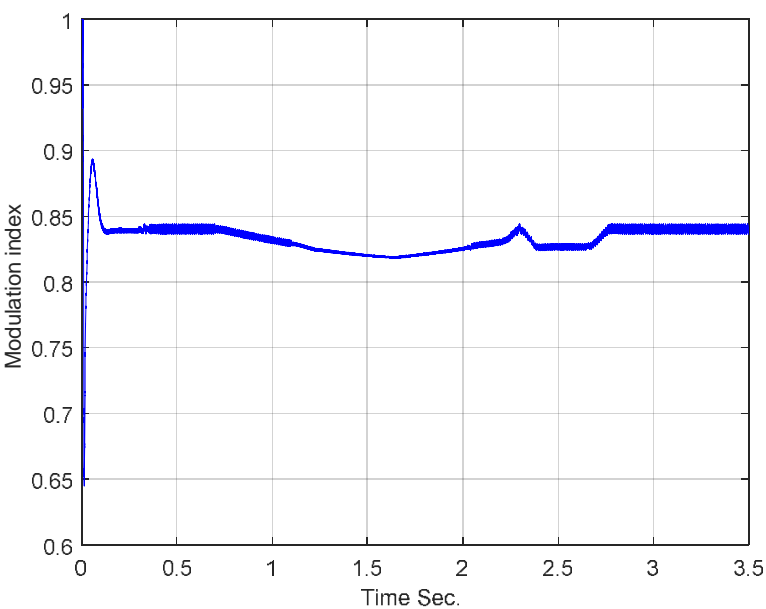

Fig.9. Operation the modulation index

Fig.11. The output power from two PV arrays 


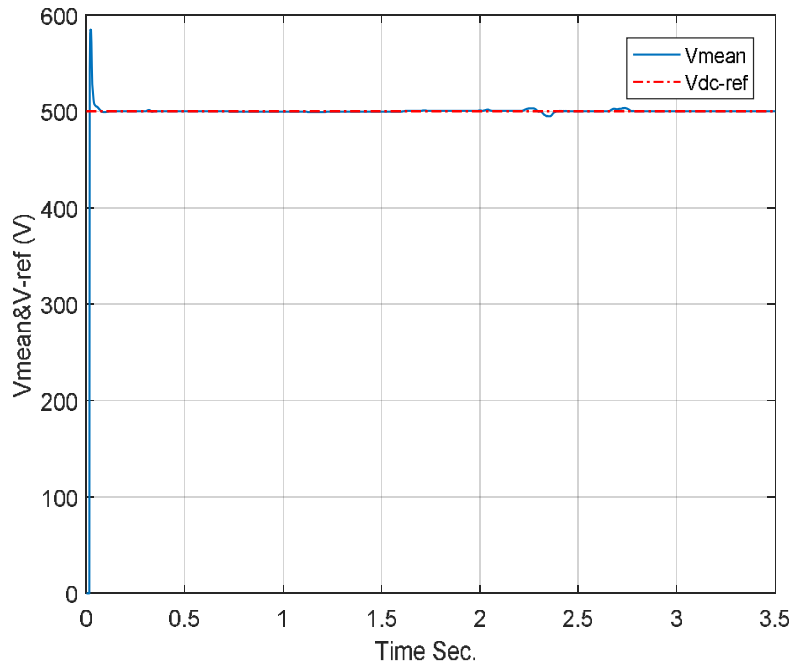

Fig.10. Reference voltage and output voltage of DC/DC converter

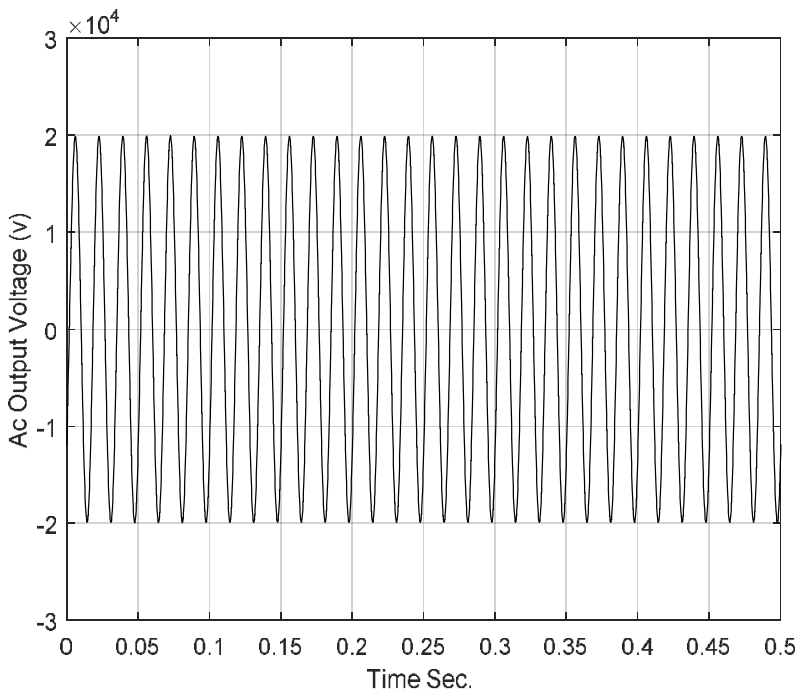

Fig.12 Ac output voltage waveform with grid connection

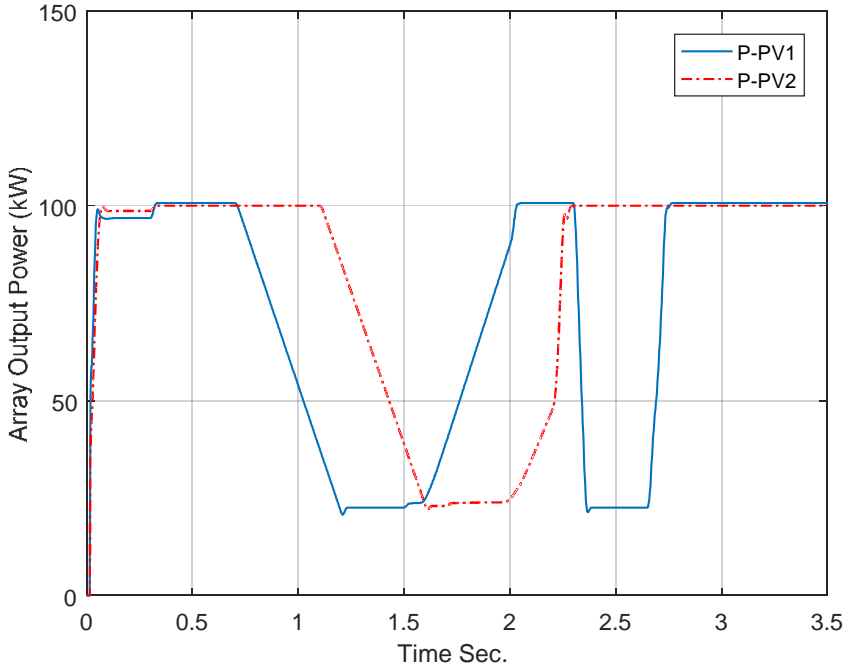

Fig.11. The output power from two PV arrays

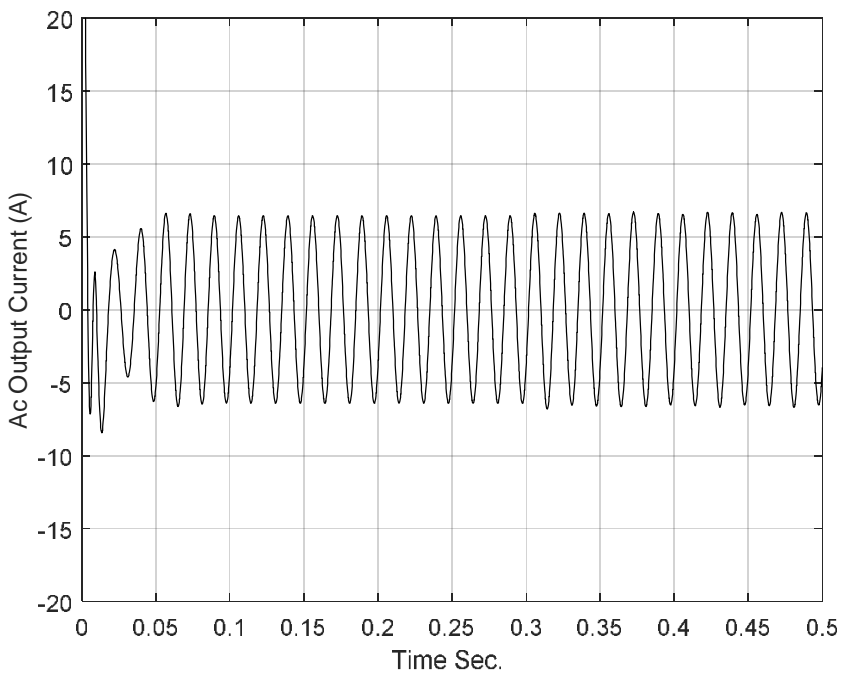

Fig.13 Ac output current waveform with grid connection 


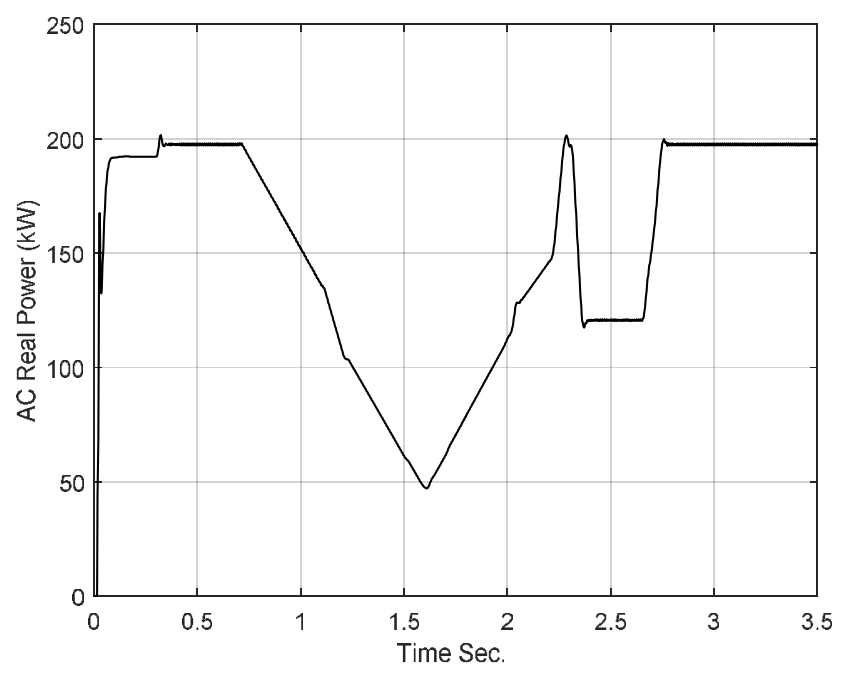

Fig.14 AC real power delivered to grid.

\section{6-CONCLUSION}

In this paper modelling and simulation of PV system with Perturb and Observe MPPT algorithm On-grid photovoltaic system is performed on MATLAB/SIMULINK. The MPPT algorithm is discused and perform the simulation with that interruption technique. By this algorithm can keeping on tracking the maximum power from the PV system that can be deliverd to the grid. The different waveforms that obtained from simulation are presented which proves the result of accomplishment MPPT. Pay attention of the execution of the Perturb and Observe MPPTs under the irradiance changes, it very well may be think about that this kind of MPPT controller tracks maximum power just while irradiance remains settled. The consequences demonstrate that the followed estimations of PV output voltage, PV current, help converter output voltage and obligation factor from the P\&O.

\section{REFERENCES}

[1] B. K. Bose, "Energy, environment, and advances in power electronics," IEEE Trans. Power Electron., vol. 15, no. 4, pp. 688-701, Jul. 2000.

[2] F. Blaabjerg, C. Zhe, and S.B.Kjaer "Power electronics as efficient interface in dispersed power generation systems" IEEE Trans. Power Electron,vol.19,no.5,pp.1184-1194,Sep. 2004.

[3] Kim, I.S.; Kim, M.B.; Youn, M.J. New maximum power point tracker using sliding-mode observer for estimation of solar array current in the grid-connected photovoltaic system. IEEE Trans. Ind. Electron. 2006, 53, 1027-1035.

[4] Cabal, C.; Alonso, C.; Cid-Pastor, A.; Estibals, B.; Seguier, L.; Leyva, R.; Schweitz, G.; Alzieu, J. Adaptive digital MPPT control for photovoltaic applications. In Proceedings of the ISIE, Vigo, Spain, 4-7 June 2007; pp. 2414-2419.

[5] Sera, D.; Kerekes, T.; Teodorescu, R.; Blaabjerg, F. Improved MPPT method for rapidly changing environmental conditions. In Proceedings of the IEEE, Montreal, QC, Canada, 9-13 July 2006; pp. 1420-1425.

[6] Mohanty, S., Subudhi, B. \& Ray, P. K. (2016) A New MPPT Design Using Grey Wolf Optimization Technique for Photovoltaic System under Partial Shading Conditions. IEEE Trans. Sustainable Energy, 7(1), 181-188.

[7] Villalva, M. G., Gazoli, J. R. \& Filho, E. R. (2009) Comprehensive Approach to Modeling and Simulation of Photovoltaic Arrays. IEEE Trans. Power Electronics, 24(5), 11981208.

[8] Femi, N,Petrone, G., Spagnuolo, G. \& Vitell, M. (2005) Optimization of Perturb and Observe Maximum Power Point Tracking Method. IEEE Trans. Power Electronics, 20(4), 963-973. 
[9] Zainuri, M. A. A. M., Radzi, M. A. M., Soh, A. C. \& Rahim, N. A. (2014) Development of adaptive perturb and observe-fuzzy control maximum power point tracking for photovoltaic boost dc-dc converter. IET Renewable Power Generation, 8(2), 183-194.

[10] Dileep, G. \& Singh, S. N. (2015) Maximum power point tracking of solar photovoltaic system using modified perturbation and observation method. Renewable and Sustainable Energy Reviews, 50, 109-129.

[11] Piegari, L. \& Rizzo, R. (2010) Adaptive perturb and observe algorithm for photovoltaic maximum power point tracking. IET Renewable Power Generation, 4(4), 317-328.

[12] Eltawil, M. A. \& Zhao, Z. (2013) MPPT techniques for photovoltaic applications. Renewable and Sustainable Energy Reviews, 25, 793-813.

[13] Hejri, M.; Mokhtari, H. On the Comprehensive Parametrization of the Photovoltaic (PV) Cells and Modules. IEEE J. Photovolt. 2017, 7, 250-258 